\title{
Rancang bangun alat pendeteksi intensitas cahaya berbasis Sensor Light Dependent Resistance (LDR)
}

\author{
Verna A. Suotha*, Handy I.R. Moseya*, Richard Ch. Tellenga \\ aJurusan Fisika, FMIPA, Unsrat, Manado
}

\begin{tabular}{l} 
K A T A K U N C I \\
\hline Sensor LDR \\
Luxmeter \\
Arduino
\end{tabular}

\begin{abstract}
A B S T R A K
Telah dibuat alat pendeteksi intensitas cahaya berbasis Sensor Light Dependent Resistance (LDR) dengan modul arduino Nano V3. Alat ini dibuat dengan memanfaatkan perubahan resistansi pada sensor LDR ketika dikenakan cahaya. Sensor Light Dependent Resistance (LDR) ini belum dikalibrasi sesuai standar pabrik, sehingga digunakan alat ukur intensitas cahaya luxmeter L200 yang sudah terstandarisasi untuk proses kalibrasi alat. Alat kemudian di program dengan software Open-Source arduino agar hasil pembacaaan alat dapat ditampilkan pada layar LCD 16x2. Hasil yang didapat yaitu pada saat belum terkalibrasi, alat luxmeter berbasis sensor LDR ini pembacaannya berbeda jauh dengan Luxmeter yang terstandar berkisar antara 1:1,5 dan setelah dikalibrasi error yang dihasilkan pada sensor ini mengecil dan pembacaan sensor LDR mendekati dengan alat ukur luxmeter L200 yang sudah terstandarisasi.
\end{abstract}

\begin{tabular}{l} 
K E Y W O R D S \\
\hline LDR Sensor \\
Luxmeter \\
Arduino
\end{tabular}

A B S T R A C T

Light intensity detection devices have been developed based on Light Dependent Resistance (LDR) sensor with arduino Nano V3 module. This tool is made by exploiting the resistance change in the LDR sensor when it is applied with light. This Light Dependent Resistance (LDR) sensor has not been calibrated to factory standards, so a standard L200 luxmeter L200 intensity gauge has been employed for calibration process. The tool is then in the program with the arduino Open-Source software so that the reading results of the tool can be displayed on the 16x2 LCD screen. The results obtained when not yet calibrated, are differ greatly with the standardized Luxmeter which ranged from 1: 1.5 and after been calibrated the error result in this sensor is become smaller and the constructed LDR sensor readings are close to standardized luxmeter L200.

\begin{tabular}{l}
\hline TERSEDIA ONLINE \\
\hline 01 Februari 2018 \\
\hline
\end{tabular}

\section{Pendahuluan}

Energi merupakan salah satu kebutuhan yang penting dalam kehidupan manusia (Brandon \& Lewis, 1999). Peningkatan kebutuhan energi untuk kebutuhan manusia semakin hari semakin meningkat (Liodakis, 2010). Penelitian dari Beretta 2015 menyatakan bahwa penggunaan energi didunia naik dua kali lipat pada 3 dekade terakhir. Tercatat bahwa pada tahun 2004 sekiranya ada $77.8 \%$ penggunaan energi dari bahan bakar fossil (32.8\% oli, $21.1 \%$ gas, $24.1 \%$ dari batu bara) dan kemungkinan akan bertambah. Hal ini menyebabkan konsentrasi $\mathrm{CO} 2$ di atmosfir akan naik, temperatur di bumi pun akan naik dan kerusakan lingkungan ekologi seperti hutan terbakar dan lain-lain pun akan lebih sering terjadi (Chen \& Wu, 2015). Untuk menepis permasalahan tersebut, para peneliti mendapat solusi-solusi seperti energi terbarukan berbahan dasar biomassa dan power-saving atau hemat daya (Painuly, 2000; Sudhakar et all, 2013).

Hemat daya merupakan salah satu pertimbangan utama dikarenakan sumber-sumber daya alam sekarang yang mulai berkurang (Sudhakar, 2013). Menurut penelitian dari Ross 2000 menyatakan daya yang hilang dari 10 rumah berkisar antara 14 - $169 \mathrm{~W}$ dengan rata-rata $67 \mathrm{~W}$, hal ini diakibatkan oleh Standby Power. Standby Power sering terjadi dimana manusia cenderung 
tidak mencabut alat elektronik yang masih terkoneksi dengan energi listrik atau secara terusmenerus mengonsumsi daya ketika tidak bekerja sesuai dengan fungsi utama alat tersebut.

Dikutip dari penelitian Amin et all 2011, Standby Power dari lemari pendingin menempati posisi tertinggi dengan $10 \mathrm{~W}$ dibandingkan dengan laptop, microwave, Televisi 32 Inch, CPU \& LCD Monitor dan bola lampu. Tetapi total konsumsi energi listrik terbanyak diberikan pada bola lampu dengan $700 \mathrm{kWh} /$ tahun yang tidak memiliki Standby Power. Hal ini disebabkan oleh pemakaian bola lampu yang kurang efisien dan kecenderungan manusia yang secara terus menerus menyalakan lampu disepanjang hari.

Lampu merupakan sumber cahaya yang digunakan untuk membantu aktivitas manusia setiap hari. Saat ini pencahayaan lampu hanya dikontrol dengan dua keadaan yaitu ON dan OFF hal ini tentunya kurang efisien baik dari segi energi maupun pada aktivitas manusia itu sendiri Pencahayaan menjadi salah satu factor dalam kenyamanan manusia untuk beraktivitas dan penerangan yang buruk akan berdampak negatif pada mata manusia seperti kelelahan mata, pegal pada mata, sakit kepala di sekitar mata. Solusi untuk mengurangi konsumsi listrik dari bola lampu yaitu dibuatnya lampu LED yang mampu menekan efisiensi dari bola lampu biasa. Tetapi kekurangan dari lampu LED sendiri adalah sudut penerangannya yang sempit dan sulit untuk memancarkan cahaya yang merata ke segala arah. Berbeda dengan lampu biasa, lampu LED biasa disebut sebagai bola lampu yang tidak memiliki arah pencahayaan (Ishibashi, 2004).

Tujuan penelitian ini yaitu untuk membuat alat pengontrol pencahayaan lampu untuk mengatur tingkat pencahayaan lampu pada ruangan berbasis mikrokontroler dan berdasarkan standard intensitas cahaya yang dibutuhkan disetiap ruangan.

\section{Material dan Metode}

\section{Sensor LDR}

Sensor cahaya LDR (Light Dependent Resistor) merupakan alat photosensitive yang memiliki nilai resistansi bervariasi tergantung pada intensitas cahaya yang mengenai sensor tersebut (Skinner, 1991). Sensor LDR mengukur intensitas cahaya sebagai sinyal analog dan semakin besar intensitas cahaya yang diberikan maka akan semakin kecil resistansi yang ada pada sensor LDR itu sendiri (Kumar \& Suryanarayana, 2014)

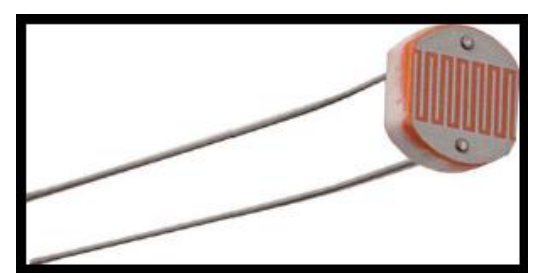

Gambar 1 . Sensor LDR

\section{Arduino}

Arduino adalah single-board rangkaian berbasis mikrokontroler, arduino digunakan untuk berinteraksi dengan objek seperti sensor, push button dan mengontrol motor dan lain-lain (Pradeep,2014). Arduino berbasis mikrokontroler ATMEGA328P dapat berkomunikasi menggunakan port serial dengan device seperti modul Wi-Fi, Bluetooth, Komputer dan lain sebagainya (Tat \& Haur, 2013)

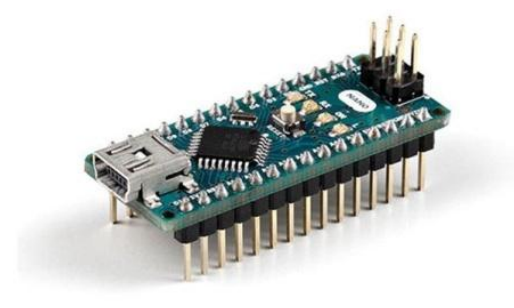

Gambar 2. Arduino Nano V3

Luxmeter

Luxmeter merupakan alat untuk mengukur intensitas penerangan cahaya dalam satuan lux (Im/m^2) (Nomoto et all, 1994).

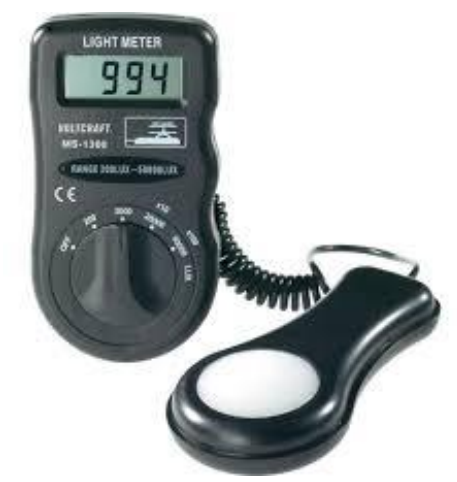

Gambar 3. Alat Ukur Intensitas Cahaya Luxmeter

Pada penelitian ini alat dikalibrasi terlebih dahulu menggunakan alat ukur luxmeter L200 merek KIMO yang telah terstandarisasi oleh pabrik, dengan cara memberikan cahaya kepada alat ukur luxmeter dan sensor LDR secara bersamaan kemudian diukur besar resistansi yang dihasilkan oleh sensor LDR. Data proses kalibrasi ini diambil di beberapa titik pada kondisi-kondisi : Gelap dengan tidak memberikan pencahayaan sama sekali pada sensor LDR dan alat luxmeter, dalam kondisi ini sensor dan alat luxmeter ditutup didalam kotak hitam. Redup dengan memblok beberapa titik cahaya yang masuk pada ruangan. Sedang dengan kondisi pencahayaan yang masuk pada ruangan tertutup. Terang dengan kondisi memberikan penerangan flashlight pada sensor dan alat luxmeter, dan Terang Sekali dengan memberikan penerangan lampu dengan jarak yang dekat pada sensor dan alat tersebut. 


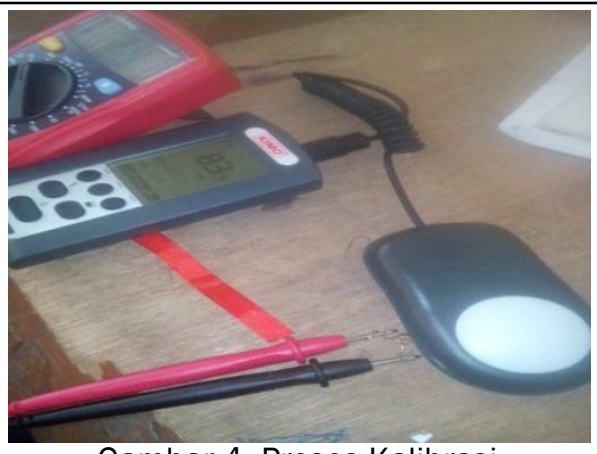

Gambar 4. Proses Kalibrasi

Kemudian alat dirangkai pada papan project board dengan gambar rangkaian sebagai berikut :

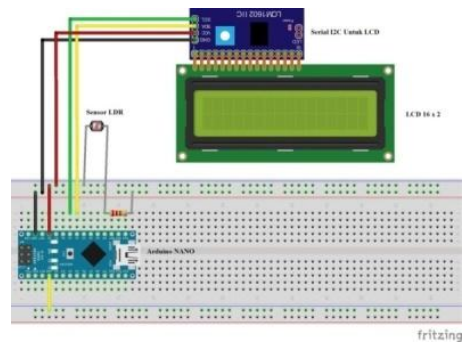

Gambar 5. Rangkaian pendeteksi intensitas cahaya

Dengan keterangan :

- $\quad$ Pin A5 Arduino Nano ke pin SCL dari I2C LCD

- $\quad$ Pin A4 Arduino Nano ke pin SDA dari I2C LCD

- Kaki LDR dihubungkan ke Resistor

- Kaki LDR yang tidak dihubungan dengan resistor di pin AO pada Arduino Nano

- Kaki Resistor yang tidak dihubungkan dengan LDR ke GND

Dengan LCD 16x2 yang sudah dilengkapi dengan I2C yang akan menampilkan hasil data yang dibaca oleh sensor LDR dan Port dari laptop sebagai PPower Supply alat. Setelah selesai dirangkai, alat kemudian di program menggunakan Software opensource dari arduino.

\section{Hasil dan Pembahasan}

Pada saat proses kalibrasi, data kemudian diolah menggunakan Microsoft Excel untuk mendapatkan linearitas dan di interpretasikan dengan grafik.

Tabel 1 Data Kalibrasi

\begin{tabular}{|r|r|l|l|}
\hline $\begin{array}{c}\text { Resistansi } \\
(\text { Ohm })\end{array}$ & $\begin{array}{c}\text { Lux } \\
\left(\mathrm{Im} / \mathrm{m}^{\wedge} 2\right)\end{array}$ & \multicolumn{1}{|c|}{$\log r$} & \multicolumn{1}{|c|}{$\log \operatorname{lux}$} \\
\hline 1352000 & 0.1 & 6.13097669 & -1 \\
\hline 45000 & 4 & 4.65321251 & 0.60205999 \\
\hline 6900 & 14.5 & 3.83884909 & 1.161368 \\
\hline 3350 & 49.4 & 3.52504481 & 1.69372695 \\
\hline 1240 & 297.1 & 3.09342169 & 2.47290265 \\
\hline 163 & 1055000 & 2.2121876 & 6.02325246 \\
\hline
\end{tabular}

\begin{tabular}{|c|}
\hline slope \\
\hline-1.604568157 \\
\hline$y$-intercept \\
\hline 8.0977263 \\
\hline$A=$ \\
\hline 125235178.3654270 \\
\hline$B=$ \\
\hline-1.604568157 \\
\hline
\end{tabular}

\section{Log R vs Log Lux}

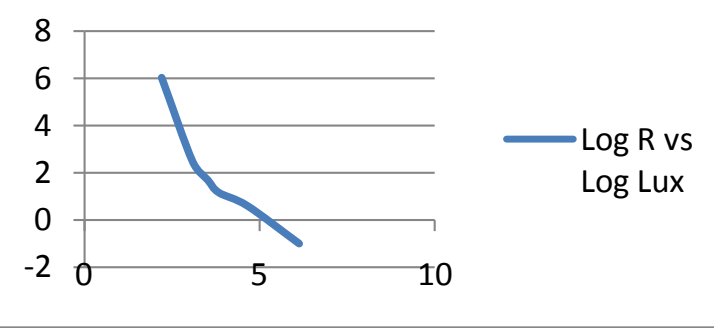

Gambar 6. Grafik Log R vs Log Lux Coding alat dengan software sebagai berikut:

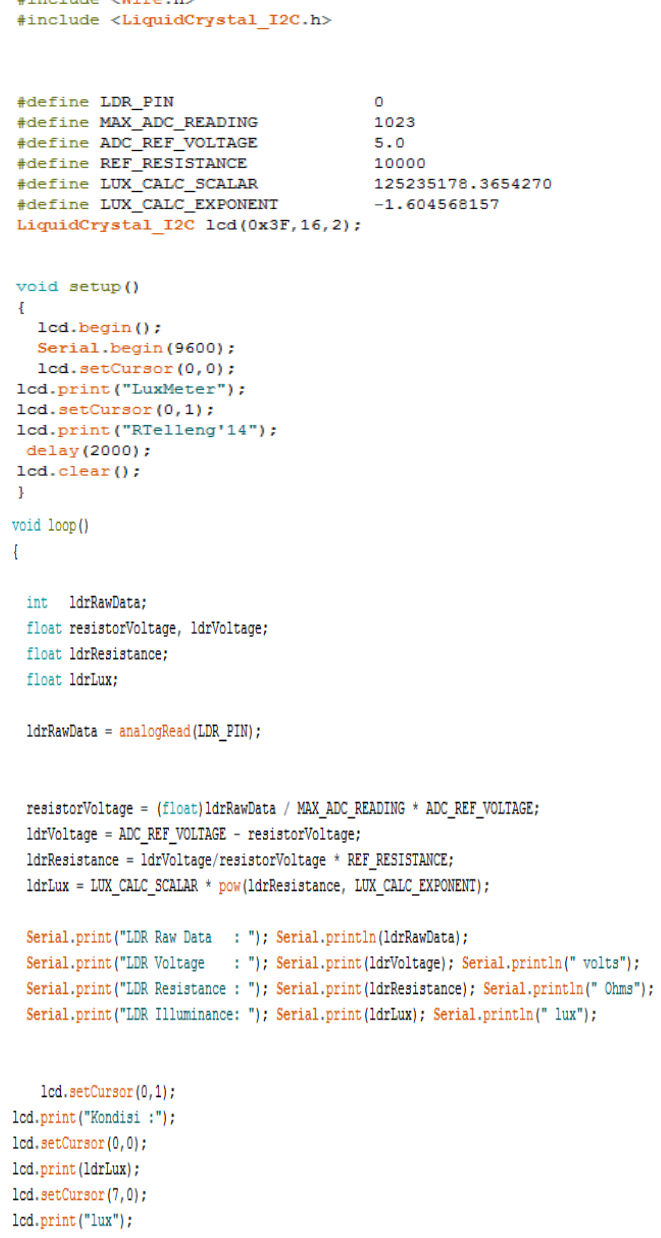




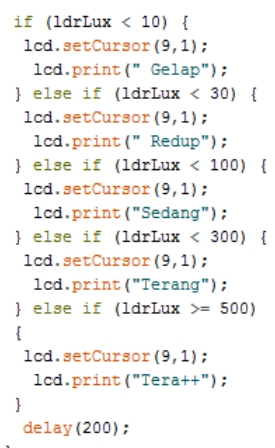

Hasil saat merangkai alat kemudian dikemas dalam box.

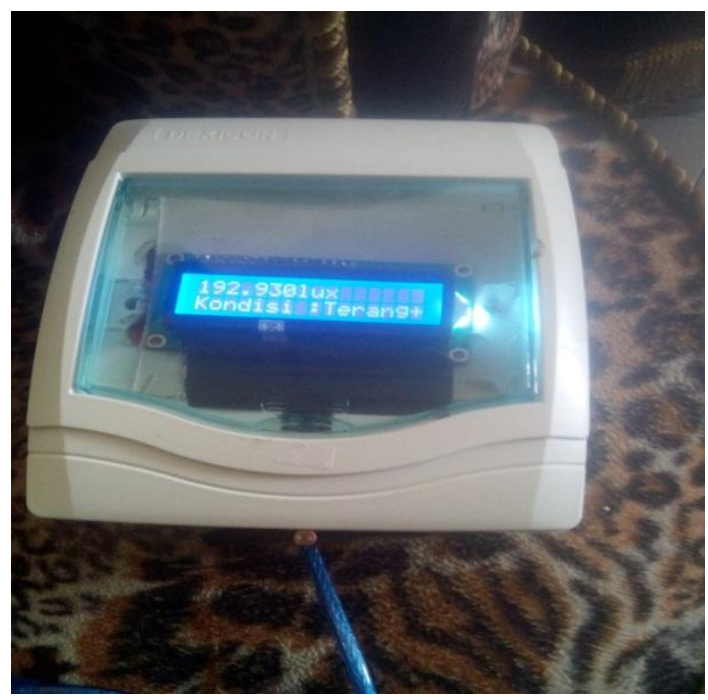

Gambar 7. Hasil rangkaian setelah dikemas

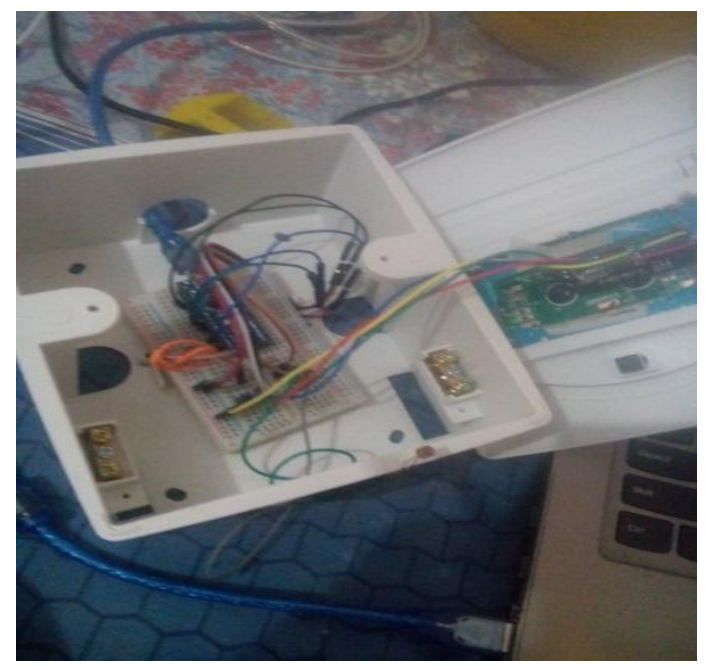

Gambar 8. Tampak Dalam

Hasil pembacaan alat kemudian dibandingkan dengan luxmeter tipe L200 pada kondisi yang mirip saat pada proses kalibrasi alat kemudian digambarkan dalam bentuk grafik saat sensor LDR belum terkalibrasi dan saat sensor LDR telah dikalibrasi

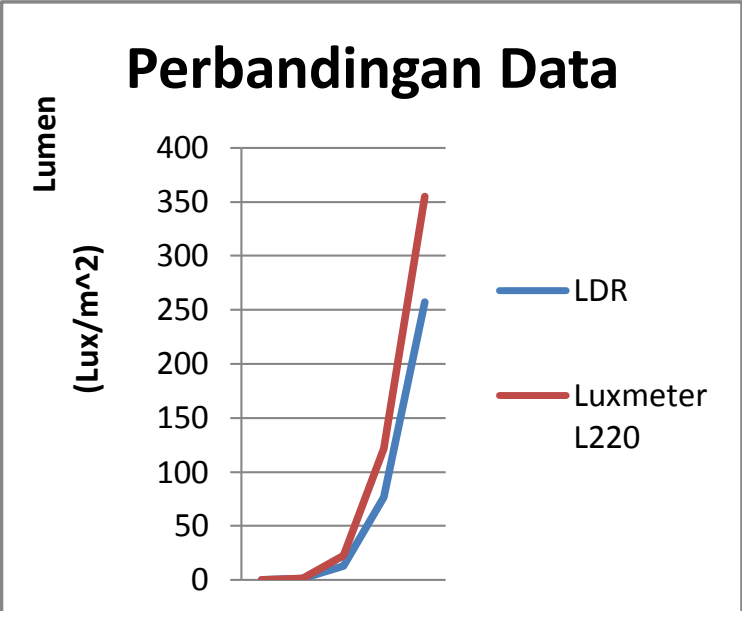

Gambar 8. Luxmeter dari LDR

(Belum terkalibrasi) vs Luxmeter L200

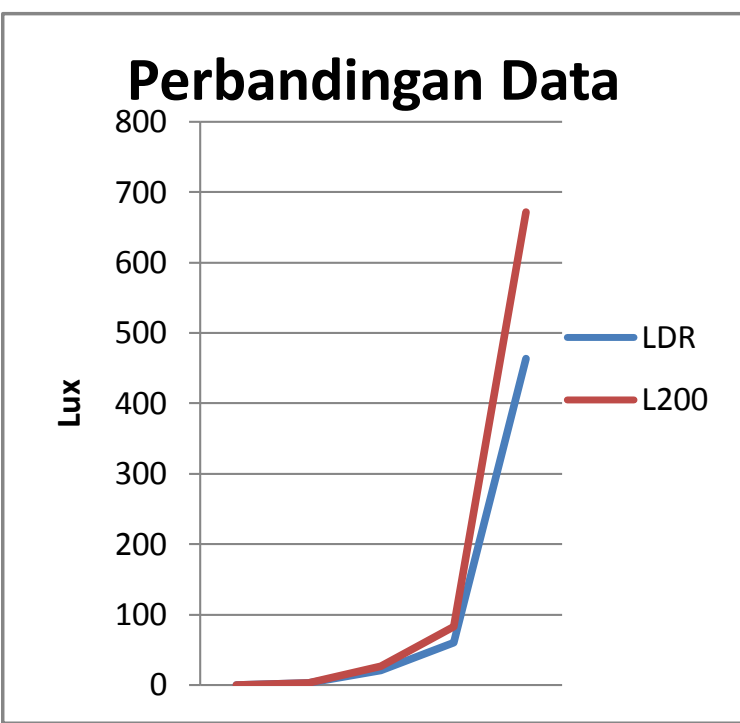

Gambar 9. LDR Luxmeter (Terkalibrasi) vs Luxmeter L200

Dalam penelitian ini, pembuatan luxmeter menggunakan sensor cahaya LDR (Light Dependent Resistance) disusun dengan resistor sehingga menghasilkan tegangan pembagi antara sensor LDR dengan resistor, disini digunakan resistor bernilai 10KOhm dan dengan LCD 16x2 sebagai display. Dengan persamaan Lux sama dengan A dikali Resistansi LDR pangkat $\mathrm{B}$, didapat data dalam bentuk grafik. ada 2 grafik yang bisa dilihat pada bab Hasil yaitu yang pertama adalah Grafik dimana Luxmeter belum dilakukan kalibrasi dengan kata lain slope A dan B nya diambil dari internet saja dan yang kedua adalah LDR Luxmeter yang sudah terkalibrasi menggunakan alat Luxmeter tipe L200 yang sudah terstandarisasi.

Pada proses kalibrasi ini diambil 4 keadaan yaitu gelap-redup-terang-terang sekali dan dilakukan pada ruangan tertutup (Indoor). dan didapat hasil seperti diatas, yaitu untuk yang belum terkalibrasi ketika LDR Luxmeter dan Luxmeter diberi cahaya yang terang sampai terang sekali itu perbedaannya agak besar, dikarenakan setiap sensor LDR 
Luxmeter memiliki linearitas yang berbeda-beda sehingga slope A dan B yang didapat melalui internet itu tidak cocok dengan sensor LDR yang digunakan pada laporan ini. Ketika dilakukannya kalibrasi dengan mengukur resistansi pada sensor cahaya menggunakan Multimeter digital dan diberikan 4 kondisi pada LDR dan L200 untuk mengukur lux seperti diatas, didapat slope A dan B yang berbeda.

Kemudian ketika di implementasikan ke sensor LDR melalui program yang menggunakan Arduino Nano V3 dan datanya di olah dengan Microsoft Excel, errornya mengecil tetapi perbedaannya masih terlihat pada grafik. Alasan hal ini terjadi yaitu kesalahan saat melakukan kalibrasi paparan cahaya tidak kena secara utuh pada Luxmeter atau sensor cahaya LDR tidak terhubung dengan benar pada multimeter saat melakukan kalibrasi. Hal yang mungkin terjadi juga yaitu alat Luxmeter L200 yang sudah dilengkapi filter yang dapat meng-cut error saat pengukuran dan sensor dari Luxmeter L200 yang memiliki sensitivitas yang lebih tinggi dibandingkan sensor LDR.

\section{Kesimpulan}

Alat luxmeter berbasis sensor cahaya LDR berhasil dibuat dan sudah dibandingkan dengan alat ukur Luxmeter yang sudah terstandarisasi meskipun masih ada perbedaan pada saat pengambilan data tetapi error tersebut dapat diperkecil dengan mengkalibrasi sensor LDR dengan bantuan alat Luxmeter L200.

Dari rangkaian yang dihubungkan dan data yang diolah dapat disimpulkan bahwa sensor cahaya LDR dapat menjadi dasar pembuatan alat ukur Luxmeter dengan cara yang pengkalibrasian yang benar sehingga didapat data yang persis dengan data pada alat Luxmeter yang sudah diuji dan di standarisasi oleh pabrik.

\section{Daftar Pustaka}

Amin Nurhani. 2011. Optimasi Sistem Pencahayaan Dengan Memanfaatkan Cahaya Alami (Studi Kasus Lab. Elektronika dan Mikroprosessor ). Jurnal IImiah Foristek. Vol.1, No. 1, (2011)

Brandon \& Lewis. 1999. Reducing Household Energy Consumption and Quantitative Field Study. Journal of Envirotmental Psychology. Vol 19 (1999). 75-85.

Chen Zhuolun \& Wu Xiaowei. 2015. Analysis and Evaluation of Holistic Energy Saving for Modern Buildings. International Journal of Smart Home. Vol 9 No.2 (2015). pp. 219-230.

Foo C.Y. et all. 2015. Utilization of Reduced Graphene Oxide/Cadmium Sulfide-modified Carbon Cloth for Visible-light-prompt Photoelectrochemical Sensor for Copper (II) Ions. Journal of Hazardous Materials : Malaysia

Ishibashi Kazuo. 2001. LED Bulb. US PATENT : US20030031015
Liodakis G. 2010. Political Economy, Capitalism and Sustainable Development. Sustainability. Vol 2 (2010) 2601-2616.

Nomoto et all. 1994. Effect of Light Intensity on Polymerization of Light-cured Composite Resins. Dental Materials Journal 13(2): 198-205, 1994

Kumar V. S. S. \& Suryanarayana S. 2014. Automatic Dual Axis Sun Tracking System using LDR Sensor. International Journal of Current Engineering and Technology. Vol.4, No.5

Painuly J.P.. 2001. Barriers to renewable energy penetration; a framework for analysis. Renewable Energy. Vol 24 (2001) 73-89.

Ross J.P. \& Meier Alan. 2000. Whole-House Measurements of Standby Power Consumption. University of California. Berkeley.

Tat L.S \& Haur Y.K. 2013. Remote AC Power Control by Using Microcontroller. Journal of Telecommunication, Electronic and Computer Engineering. ISSN 2180-1843, e-ISSN 22898131.

Tonzani S. 2009. Time to change bulb. Nature. Vol 451(2009). 312.

Tongkukut S.H \& As'Ari. 2016. Analisis Tingkat Pencahayaan Ruang Kuliah Dengan Memanfaatkan Pencahayaan Alami Dan Pencahayaan Buatan. JURNAL MIPA UNSRAT ONLINE. Vol 5 (2) 108-112

Wisnu Muhammad. 2016. Rancang Bangun Alat Ukur Intensitas Penerangan Cahaya Portabel dan Nirkabel Untuk Pemetaan Pencahayaan Dalam Ruangan. UGM : Yogyakarta 